\title{
Psicoterapia lúdica de uma criança com AIDS
}

\author{
Therapy of a child with AIDS
}

\author{
Svetlana Bacellar AGUIRRE \\ Sérgio Luiz Saboya ARRUDA ${ }^{2}$
}

\begin{abstract}
Resumo
Trata-se do estudo de caso de uma criança com AIDS, atendida semanalmente em psicoterapia lúdica de orientação psicodinâmica durante um ano. São descritas e discutidas fantasias, angústias e defesas relacionadas às dificuldades emocionais de vivenciar sua doença e a perda de seus pais falecidos por complicações decorrentes da AIDS. Essa criança se expressou principalmente por meio de desenhos, utilizando inicialmente a negação como mecanismo de defesa. No decorrer do processo de ludoterapia, pôde usar outras defesas e formas de expressão. São observados sentimentos de abandono e de culpa relacionados com sua doença e com a morte dos pais, e fantasias inconscientes de haver provocado o falecimento dos genitores.
\end{abstract}

Palavras-chave: HIV; morte; psicoterapia lúdica da criança; psicoterapia psicodinâmica.

\begin{abstract}
This is a case report of a child with AIDS who has taken part into psychotherapeutic sessions for an year. Considering theemotional difficulties experienced by the patient regarding the disease as well as the loss of his parents, caused by AIDS, an analysis based on psychodynamic psychology was conducted in relation to the unconscious fantasies, anxieties and defenses. At first, the child had used denial as a defense and expressed himself mainly through drawings. Along the play psychotherapy, the child was able to use less primitive defenses and express himself in other ways, such as games and drawings. The child's suffering seemed to be a result of abandonment and guilt feelings in relation to the disease and to his parents'death, as well as to unconscious fantasies of having provoked their death.
\end{abstract}

Key words: human-immunodeficiency-virus; death; play-therapy; child-psychotherapy.

Ser vitimado por uma doença grave ou enfrentar o falecimento dos pais são acontecimentos difíceis de serem vividos e elaborados por qualquer indivíduo, devido ao envolvimento com a problemática da morte com suas perdas e lutos. No presente estudo, essas situações ocorreram simultaneamente, o que torna a dinâmica mental e o processo terapêutico mais complexos, principalmente por haverem atingido uma criança em desenvolvimento.
Neste trabalho, são discutidas fantasias, angústias e defesas de um menino de nove anos de idade em relação a sua enfermidade, a Síndrome de Imunodeficiência Adquirida (AIDS), e à perda dos pais. Espera-se que este estudo de caso possa auxiliar na compreensão de aspectos emocionais presentes em crianças com doenças potencialmente graves ou que enfrentam perdas e situações de morte, podendo ser útil a profissionais que trabalham clinicamente com seres humanos em contextos semelhantes.

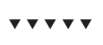

1 Psicóloga, Curso de Especialização em Psicoterapias na Infância, Departamento de Psicologia Médica e Psiquiátrica, Faculdade de Ciências Médicas, Universidade Estadual de Campinas. Campinas, SP, Brasil.

2 Professor Doutor, Departamento de Psicologia Médica e Psiquiatria, Faculdade de Ciências Médicas, Universidade Estadual de Campinas. Caixa Postal 6111, Barão Geraldo, 13081-970, Campinas, SP, Brasil. Correspondência para/Correspondence to: S.L.S. ARRUDA. E-mail: <saboya@unicamp.br>. 
Em seguida, são feitas considerações teóricas sobre a morte, o luto e a vivência de doenças graves, associando-as à infância, temas preparatórios para a discussão clínico-teórica do caso relatado.

\section{A morte e o luto}

O morrer e a morte são fenômenos mais abrangentes e complexos do que a simples cessação da vida. A morte pode ser precedida por um longo processo psicológico e orgânico. Na esfera emocional, é importante que se considere a ansiedade associada ao processo de adoecimento, as ameaças inerentes à aproximação do fim, e uma série de acontecimentos experienciados ao longo da vida.

Para Taschetto, Teixeira e Kiperman (1994), Winnicott não se deteve em uma idéia biológica da morte, mas interessou-se pela morte psíquica, rompendo com o pensamento de morte como algo pré-determinado ou desejado. O"problema fundamental não é o conflito entre amor e ódio, ou vida e morte, mas entre o ser e o aniquilamento, entre o amor e o temor" (p.192).

Winnicott (1963/2000) afirma que, respeitadas as variações individuais, o medo da morte - assim como o medo do colapso e da solidão - pode ser considerado um medo de um acontecimento passado que já ocorreu, mas que ainda não pôde ser experienciado.

Celeri e Outeiral (2005) comentam que Winnicott sempre se posicionou criticamente em relação à pulsão de morte. O indivíduo não emerge do inorgânico, o oposto da vida não é a morte. Nos estágios iniciais do desenvolvimento emocional, a morte significa a"perda do ser em razão de uma reação prolongada contra uma intrusão ambiental" (p.437).

O longo processo do viver em direção à morte - que inclui o adoecer e inúmeras situações inconscientes de morte psíquica, de perdas, de lutos, e de cuidados não suficientemente adequados - deve ser discriminado da vivência da morte propriamente dita. Aquele processo já está presente desde a infância, prolonga-se por toda a existência humana e é preparatório do fim da vida.

Freud (1915/1974b) afirma que, do ponto de vista do inconsciente, os seres humanos relutam em acreditar na própria morte, julgando-se imortais. Em "Luto e melancolia", Freud (1915/1974a) chama de luto o processo inconsciente de elaboração da perda de um ente querido, consistindo num período a ser superado dentro de um intervalo de tempo. O luto é doloroso, ocorre contra a vontade do sujeito, implica sentimento de vazio.

Segundo Torres (2002), a criança sabe mais a respeito da morte do que geralmente os adultos supõem. A idade cronológica, o desenvolvimento cognitivo e situações de confronto com a morte são importantes na aquisição dos conceitos de irreversibilidade (o corpo não vive após a morte), não-funcionalidade (cessação das atividades do corpo após a morte) e universalidade (tudo que é vivo morre).

Assuntos que giram em torno do começo e do fim da vida fazem parte da inesgotável curiosidade da criança. O conceito de morte ainda não é claro, já que as crianças criam hipóteses a respeito da morte e do morrer, conforme predomine a fantasia ou a realidade (Hug-Helmut, 1998).

O silêncio do adulto a respeito da morte influencia a percepção da morte e o luto da criança. Ao se esconderem fatos importantes, ataca-se a capacidade de pensar da criança, deixando marcas prejudiciais em seu desenvolvimento. Da mesma forma, ocultar a morte dificulta o trabalho de luto (Aberastury, 1984).

A criança é muito influenciada pelo que lhe é dito e como é dito. Para ajudá-la no processo de luto, é importante manter com ela uma comunicação sincera e direta; garantir o tempo necessário para o luto; e assegurar-lhe a proteção necessária (Torres, 2002).

\section{A vivência de uma doença grave}

O homem reage de formas diferentes às doenças em função de vários fatores: o significado pessoal e subjetivo que a enfermidade desperta no paciente, as características de personalidade, as circunstâncias sociais, a natureza da patologia e o tratamento realizado (Botega, 2006).

Kübler-Ross (1989) concluiu que os pacientes passam por diferentes estágios a partir do momento que sabem que estão com doença grave e que correm risco de vida. Tais estágios são: negação, isolamento, raiva, barganha, depressão, aceitação, esperança. 
Ao comentar a forma como o ser humano lida com a morte, Cassorla (1991) afirma o seguinte: "não podemos viver bem, se negamos nossa finitude. A morte faz parte da vida, e se a ignoramos já não vivemos" (p.21).

Sobre a consciência que uma criança apresenta da sua enfermidade, lencarelli (1997) relata o caso de um paciente de dez anos de idade em psicoterapia que sabia ter tumor na coluna. Em nenhum momento, ele ignorava seu estado e a possibilidade de morrer.

A compreensão consciente é um componente importante da resposta da criança à doença. Contudo, as fantasias inconscientes podem alterar a percepção e a compreensão que ela tem de sua doença, dos procedimentos médicos e do tratamento (Celeri, Jacintho \& Straus, 2006).

Algumas crianças gravemente doentes podem sentir-se culpadas ou castigadas pela doença. Também sentem revolta e ansiedade, podendo tais sentimentos influenciar na adesão ao tratamento (Weininger, 1996).

\section{AIDS e psicoterapias}

Na literatura científica, é grande o número de artigos sobre a AIDS, com predomínio dos estudos sobre a prevenção, o diagnóstico ou o tratamento dos aspectos orgânicos dessa enfermidade. São mais comuns trabalhos referentes à idade adulta e à adolescência, sendo bem menos freqüentes os estudos sobre a infância.

Embora os artigos sobre os aspectos psicológicos e terapêuticos dos pacientes soropositivos sejam bem menos freqüentes, há trabalhos que se apóiam no referencial psicanalítico, inclusive estudos de caso.

Souza (1992) descreve um grupo de reflexão para profissionais da saúde que permitiu a discussão de angústias relacionadas com as dificuldades de comunicar o diagnóstico da doença e com a vivência de impotência terapêutica, assinalando que se precisa entender o paciente como um sujeito. Moreno e Reis (2002) defendem que o profissional que atende pacientes com AIDS precisa sair do lugar de curador e assumir o de cuidador.

Dentre os relatos de caso, Cedaro (2005) entrevista quatro pacientes adultos com AIDS, comparando a vivência da doença a uma ferida narcísica. Tonin (2001) comenta a importância dos aspectos transferenciais e contratransferenciais, quer como propulsores da terapia, quer na resistência à análise de um paciente terminal adulto.

Gewirtz e Gosssart-Walker (2000) alertam que crianças e familiares soropositivos necessitam de uma série de cuidados para poderem crescer emocionalmente, para lidarem com a perda dos pais, com mudanças de lares, segregações e estigmas. Mencionam a importância de serviços com profissionais que possam oferecer suporte, psicoterapia e até visitas domiciliares, de forma integrada com a comunidade.

Gunther, Crandles, Williams e Swain (1998) descrevem um programa de suporte psicossocial com grupo psicoterápico para adolescentes cujos pais são portadores de HIV, em que se trabalhava a dependência-independência e o processo de separação-individuação.

Em estudo com crianças soropositivas hospitalizadas, Baricca (1998) mostra a importância de se falar com as mesmas sobre o seu corpo, medos, angústias, desejos e o próprio existir. Silva (2005) relata a psicanálise de um menino soropositivo de oito anos de idade, concluindo que a constância e a idealização da analista foram importantes na integração de aspectos bons e maus do próprio "self", permitindo transformar a destrutividade em uma agressividade favorável à vida.

Aronson (1996) discute problemas no suporte a cinco crianças que perderam os pais por AIDS. Fala do tempo insuficiente para poderem estabelecer vínculos com instituições e pessoas que delas cuidam, e da presença de sentimentos ambivalentes da sociedade e dos cuidadores. Aponta para a necessidade de se manter uma comunicação aberta com essas crianças e de, no processo terapêutico, permitir que as mesmas possam falar e perguntar livremente, criando-se um ambiente de confiança e de aceitação.

\section{Método}

Este estudo é uma pesquisa qualitativa e descritiva que utiliza o método-clínico qualitativo, definido como um meio científico de conhecer e interpretar as significações de naturezas psicológicas (Turato, 2003). 
É relatado o atendimento de uma criança em psicoterapia lúdica psicodinâmica, efetuado em um ambulatório de um serviço público. A paciente foi selecionada por ter diagnóstico de AIDS, por apresentar dificuldades emocionais associadas à doença e por haver perdido a mãe e o pai. As sessões de psicoterapia foram semanais, com duração de 45 minutos.

Para a realização do estudo de caso, foram aproveitadas informações contidas no prontuário médico da criança, incluindo as entrevistas para anamnese, e a hora de jogo diagnóstica. Além disso, foram utilizadas informações provenientes das sessões de ludoterapia e das supervisões. Após 12 meses de tratamento, foi feita a análise do material clínico, relacionando-se os conteúdos (fantasias, ansiedade e defesas) que a criança expressava durante a psicoterapia lúdica, com os conhecimentos teóricos, em consonância com o método clínico (Calil \& Arruda, 2004).

Dentre as principais limitações deste trabalho, citam-se: a) ser esse um estudo que relata apenas uma pequena parte da ludoterapia, o que nem sempre permite uma compreensão integral de todos os conteúdos e significados presentes no processo terapêutico; b) por ser um estudo de caso único, as discussões e considerações finais deste trabalho não devem ser generalizadas.

OTermo de Consentimento Livre e Esclarecido, assinado pelo responsável pela criança, foi aprovado pelo Comitê de Ética em Pesquisa, conforme a resolução 196/96 do Conselho Nacional de Saúde.

Para a realização da psicoterapia lúdica psicodinâmica, utilizaram-se os princípios da técnica do brinquedo criada por Melanie Klein (1955/1980), que visam à compreensão das fantasias, angústias e defesas inconscientes expressadas no brincar. Utilizou-se uma caixa com brinquedos, usados unicamente pelo paciente nas sessões.

\section{Resultados e Discussão}

\section{História breve do paciente}

Léo, nome fictício de uma criança de nove anos de idade, adquiriu o vírus HIV na gestação (contaminação vertical). A descoberta da condição de soropositivo ocorreu aos sete anos de idade, quando do diagnóstico da doença dos pais. A mãe morreu um ano depois e o pai faleceu no ano seguinte à perda da esposa, ambos por complicações decorrentes da AIDS. Então, a tia tornou-se a representante legal do sobrinho.

Na primeira entrevista, Léo veio acompanhado da tia, com a queixa de receber pouca atenção e de não se sentir gostado. Ele ficara assim após o falecimento dos pais.

Léo faz acompanhamento médico periódico, desde o diagnóstico da doença, no setor de imunodeficiência secundária do hospital. É medicado com anti-retroviral, já teve pneumonia duas vezes, mas não apresenta outras complicações.

\section{Descrição e análise resumida da terapia}

Para melhor compreensão dessa parte do estudo, que envolve a relação terapeuta-paciente, o material clínico é narrado e discutido na primeira pessoa, refletindo a observação da terapeuta.

Durante os primeiros cinco meses de ludoterapia, Léo comunicava-se principalmente por meio de desenhos. Posteriormente, também brincava com jogos e produzia objetos com o material lúdico. Contudo, durante a psicoterapia, a criança verbalizou pouco.

\section{Negação, angústias paranóides e destrutividade}

Em relação ao comportamento inicial de Léo, chamava atenção o comedimento. Quase não falava, sorria muito discretamente, movimentava-se dentro da sala sem fazer qualquer movimento brusco, barulho, ou falha nos seus atos.

Por isso, apesar de produzir desenhos, eu tinha a sensação de que pouco me comunicava. É importante assinalar que, muitas vezes, esses desenhos poderiam refletir o seu sofrimento, material que eu poderia não estar entendendo.

Creio que Léo chegou muito defendido e resistente. Era como se não conseguisse entrar em contato com seus conflitos, tinha que medir minuciosamente seus atos, pensamentos e sentimentos para não se expor. Em outras palavras, fazia esforço para manter 
as "coisas" no lugar, como se o contato com conteúdos internos pudesse ser perigoso. Penso que a negação estava sendo utilizada por Léo em relação tanto à sua doença, quanto à perda dos pais.

Por outro lado, o comedimento de Léo se tornava mais nítido quando efetuava certos desenhos com figuras e objetos de características ameaçadoras (paranóides), tenebrosas e/ou agressivas. Por exemplo, ora fazia gaivotas com elementos agressivos, com um traço preto muito grosso, as quais mais pareciam urubus a sobrevoarem um cemitério. Ora desenhava uma casa, que possuía a forma de um caixão. Depois que terminava esses desenhos, dizia: "acabei", e passava a furar intensamente uma bola de isopor.

Era como se Léo tivesse medo de seus atos, de sua destrutividade, aspectos que poderiam estar associados com a fantasia inconsciente de haver destruído os pais, com tudo o que tinham de bom e de ruim. Ou seja, ele poderia estar se culpando por haver destruído aquilo que fora bom.

Assim, quando seu comedimento pudesse estar representando a dificuldade de expressar um jogo ou desenho de conteúdo destrutivo e persecutório, era importante que eu pudesse entender e aceitar a sua dificuldade em trazer o material agressivo. Era importante que eu pudesse fornecer a minha pessoa como objeto de projeção e de continência, sem deixar-me ser destruída.

Para se poder usufruir a presença do outro, inclusive do terapeuta, é necessário que se tenha tido uma experiência de ter sido usufruído pelos pais ou seus substitutos, assim como ter tido a chance de desenvolver uma capacidade de usar os outros. Na análise de certos pacientes, é preciso permitir que seja dada aos mesmos a oportunidade de usar o terapeuta (Newman, 2003; Winnicott, 1968/2000).

Na anamnese obtida com a tia, havia o relato de que a mãe tinha tido pouco tempo para ficar com ele, para cuidar dele, para deixar-se ser usada por Léo, inclusive quando ele ainda era um bebê.

Outra forma de entender o comedimento de Léo pode ter relação com o preconceito da sociedade direcionado à AIDS. A família escondia a sua doença de outros familiares e amigos, tal como já havia feito com a enfermidade dos pais.

\section{Algumas reações da terapeuta}

Durante o processo ludoterápico, muitas vezes, eu não compreendia o material produzido por Léo. Posteriormente, entendi que ele fazia com que eu também negasse seus sentimentos.

Tranqüilizei-me ao ler o que Télis (1991) escreveu: "Não se pode exigir que o médico se exponha totalmente sem defesas a esses doentes. Ele, como o paciente, vai, em algumas ocasiões, precisar usar a negação, o distanciamento, o embotamento" (p.114-115). Para tratar desses pacientes, o profissional precisa conviver com a própria mortalidade e lutar contra sua onipotência.

Silva (2005) descreve o que lhe ocorreu durante a análise de um menino com AIDS. Era tomada de compaixão, pensava no sofrimento do paciente por ter sido abandonado. Angustiava-se por não ter acesso à sua história, por ter que cuidar de uma criança com uma doença ainda sem cura e que demandava muitos cuidados, alguns intrusivos.

Percebi que, no início da terapia, sentia-me receosa de tratar uma criança com AIDS, talvez pelos medos e ansiedades que os soropositivos despertam. A possibilidade de morte nos cega e perdemos a simples noção de que nenhum de nós sabe quando vai morrer.

Em um momento do processo terapêutico em que estava produzindo vários desenhos, perguntei-lhe: "Léo me conta um pouco sobre esse desenho?" Ele rapidamente disse:"Isso eu não consigo fazer!"Entendi, então, que meu papel era o de respeitar o seu "ritmo interno" e os limites de sua comunicação.

Dois pensamentos de Winnicott (1958/1983; 1968/2000) ajudam a compreender isso: a) era como se ele estivesse "usando" o material gráfico da terapia e a mim para lidar com as suas fantasias, inclusive com a própria destrutividade (Winnicott, 1968/2000), b) em certos momentos, quando eu conseguia estar ao seu lado, sustentando-o sem ter a necessidade de interpretar ou de analisar, aceitando-o como ele é, inclusive no seu silêncio, a sua capacidade de "estar só" no ambiente terapêutico foi permitida em função de sua importância para o seu amadurecimento emocional (Winnicott, 1958/1983) 


\section{A morte dos pais e a própria doença}

Em entrevista, a tia de Léo revelou que os pais dele não aceitavam os tratamentos necessários, o que faz pensar que também utilizavam processos de negação da doença. Quando do falecimento de cada um de seus pais, Léo compareceu ao velório e ao enterro. Foi-Ihe explicado que haviam morrido, que "dormiriam agora pra sempre e não voltariam mais" (fala da tia). Nesse sentido, a criança não havia sido enganada, teve a oportunidade de entrar em contato com a realidade.

Em entrevista, quando perguntado sobre o que acontecia com as pessoas que morriam, Léo falou do corpo em decomposição. Disse:"A pele solta do corpo e o osso vai acabando". A tia interrompeu e questionou: "E a alma?". Ele respondeu:"Não sei, não sente nada". A tia explicou que ficava dormindo para sempre. Léo concordou.

A respeito da percepção de Léo em relação ao risco de morte de sua enfermidade, questionei-o em entrevista, como entendia sua doença. Disse-me: "É como o médico explicou. Tem um bichinho no sangue". "E se não tomar remédio, o que acontece?", prossegui. Ele respondeu: "Não sei".

A ameaça de morte é um dos principais conflitos do doente de AIDS. Ferreira (1992) defende que a AIDS é uma morte de parte ou partes do sujeito. Completa que a negação, luto e melancolia fazem parte das alternativas usadas pelos pacientes para reagirem à perda. Devido à negação, o doente não toma contato com nenhuma de suas perdas, age como se nada estivesse acontecendo.

Cedaro (2005) considera que a impossibilidade de permanecer livre do mal é uma ferida no "eu" idealizado, pois o soropositivo sabe que será um doente pra sempre.

\section{Raiva, agressividade e revolta}

Com o fortalecimento do vínculo terapêutico, com o respeito ao seu ritmo, Léo ficou mais à vontade. Sorria, fazia barulho, chegou a perguntar sobre a minha vida, pedia reposição do material lúdico e gráfico. Deixava aparecer sua impaciência e agressividade disfarçadamente.
Como foi assinalado, após finalizar um desenho, guardava-o e, então, pegava bolas de isopor e as furava com um lápis até a hora de terminar o horário. Os desenhos também começaram a ter uma aparência mais carregada, pesada. Nessa fase, as cores vermelho e preto predominavam.

Além disso, expressava frustração e raiva quando algo diferente do que havia planejado acontecia, por exemplo, quando derrubava material no chão ou não conseguia colar, ou cortar algum material como queria. Podia agora viver a raiva e revolta na sessão. Possivelmente ele podia agora ter menos receio de suas projeções, de sua destrutividade e agressividade. Entendi que meu papel de sustentação e de continência tinha grande importância nesse processo, era mais significativo do que aquilo que viesse a analisar e a interpretar.

Um outro dado que denuncia a raiva e a revolta de Léo é que não aceitava ingerir os remédios para o tratamento da doença. A tia conta que ele escondia os medicamentos, fingia que os engolia, ou "enrolava" muito para tomá-los, exigindo muita atenção da responsável.

Uma forma de entender esse fato é a possível identificação de Léo com seus pais, que também se recusaram a ingerir os medicamentos. Raimbault (1979) defende que a perda de um dos genitores, quando vivida de forma difícil ou traumática, provoca a identificação com o objeto, enquanto durar o luto. Dessa maneira, o infante assume distintivos do pai morto, atribuindo-os a si próprio, sentindo-se próximo do genitor perdido.

A burla na ingestão do medicamento é preocupante, já que a má adesão ao tratamento é a principal causa de desenvolvimento de resistência viral às drogas (Moraes, Oliveira \& Tostes, 2006).

Na entrevista inicial, a tia contou que, para combater sua resistência em tomar a medicação, pouco adiantava explicar sobre a doença e seus riscos. Ele também comunicou sua raiva e revolta nas conversas com a responsável. Questionava-a porque tinha aquela doença:"Por que comigo?"; "Por que eu tive que nascer assim"?

Durante a psicoterapia, teve períodos em que Léo relutava menos para tomar os remédios. No entanto, em momentos de mais ansiedade, como as minhas férias e a aproximação do término da terapia, essa queixa retornava. 
Algo semelhante ocorreu com as queixas iniciais de receber pouca atenção e de não se sentir gostado. À medida que a psicoterapia caminhava, tais queixas já não eram tão significativas como quando do início da terapia, embora retornassem. Penso que houve uma maior consciência da criança em relação a alguns psicodinamismos associados, e que a tia estava sabendo lidar melhor com essas situações.

Segundo a responsável, Léo não gostava do médico infectologista. Apesar de a tia comentar que era bom profissional, atencioso; ele supostamente representava para a criança a ameaça da sua doença e do tratamento. Em outras palavras, o médico servia de alvo de suas projeções, de sua revolta contra a doença.

\section{Desenhos: afeto e fantasia de morte}

Ao analisar os desenhos produzidos por Léo, observei a constante presença de nuvens, as quais foram associadas aos pais. Com base em crenças e fantasias populares, os adultos costumam dizer para as crianças que, quando alguém morre, essa pessoa vai para o céu. Além disso, as nuvens poderiam simbolizar aspectos tenebrosos, ruins, que podem ser entendidos como representantes dos conflitos de Léo.

Em quase todos os desenhos, apareciam borboletas, as quais estavam associadas à fantasia de morte no presente. O óbito de seus pais e o temor de falecer pareciam estar representados por um inseto, fruto de metamorfose: primeiro é uma coisa e depois se transforma em outra. Primeiro o casulo, depois a borboleta.

Léo comentou que as borboletas voavam, subiam ao céu e podiam alcançar as nuvens. Talvez isso representasse a fantasia de unir-se aos pais, encontrálos novamente, já que, em muitos desenhos, havia os dois componentes juntos: as nuvens e as borboletas.

Havia outra figura que aparecia muito nos desenhos: o coração, que sempre era colocado no ar, sem estar apoiado em nada. O coração foi entendido como representando o afeto em relação aos pais, já que era desenhado sempre perto do céu.

\section{Culpa}

Só pude realmente entender como Léo se sentia em relação a seus conflitos quando desenhou uma casa.
Quando perguntado sobre o que podia me contar acerca daquele desenho, ele disse: "uma família foi embora dessa casa, porque tinha um menino chato". Algumas fantasias inconscientes do paciente começaram a se tornar claras.

Nesse momento, recordei-me de que o primeiro desenho que Léo fizera, antes de iniciar a terapia, na fase de avaliação (hora de jogo diagnóstica) foi uma casa, a qual denominou de casa abandonada. Era como se estivesse afirmando, em nível de fantasia, o seguinte: meus pais foram embora, morreram, porque eu sou chato, desobediente, manhoso. Vale lembrar que a queixa da tia era a de que ele reclamava, cobrava, ou seja, estava sendo chato.

Assim, pude entender que Léo se sentia abandonado e culpado pela morte dos pais. Poderia também estar inconscientemente fantasiando que estava doente por punição ou castigo. Creio que a ludoterapia pôde ajudá-lo a diminuir sua onipotência e a sentir-se menos culpado pelo falecimento dos genitores.

Um aspecto agravante da culpa é a ambivalência. Freud (1915/1974a) explica muito bem isso quando coloca que a perda de um objeto amoroso provoca a manifestação da ambivalência nas relações amorosas.

Kübler-Ross (1989) exemplifica:

A criança que de raiva deseja que a mãe morra, porque esta não satisfez seus desejos, ficará muito traumatizada caso isso venha de fato a acontecer, mesmo que não haja ligação alguma no tempo, com seus desejos de destruição. Sempre assumirá parte ou toda culpa pela morte da mãe ... Fui eu, sou responsável, fui má, por isso mamãe me abandonou (p.15).

\section{Presentes: sedução e medo de abandono}

Após cinco meses de ludoterapia, Léo começou a produzir cartas, nas quais desenhava corações e escrevia mensagens de amor destinadas aos tios ou a mim. Também passara a produzir objetos de palitinhos de madeira, colando-os até formar uma bandeja, um porta-lápis, ou um porta-guardanapos. Entendi que, após uma fase mais contida, agora estava trazendo conteúdos relacionados com a pulsão de vida. 
Tais objetos produzidos por Léo podiam simbolizar presentes. Sentindo-se culpado pela morte dos pais, por ser o menino "chato", não podia correr o risco de ser abandonado novamente. Tinha a necessidade de agradar os tios, agora seus cuidadores, com presentes. Precisava ser um menino "bom", merecedor de amor.

Em relação a mim, penso que também tinha a necessidade de me agradar. Não me ficou a recordação de haver me desobedecido ou me desagradado em qualquer sessão. Além disso, sempre produziu algo na sessão. Fazia um jogo de amor e sedução, contrapondo a idéia de uma criança chata e desobediente. Queria ser aceito.

Para crianças com AIDS, Baricca (1998) comenta que a existência de afeto, de cuidados, de comunicação e de estrutura familiar estável são muito importantes para minimizar os sentimentos de abandono, de solidão e a ameaça de morte, frutos da vivência dessa doença.

Ao final da psicoterapia, compreendi o pedido de amor de Léo, que fazia parte da queixa inicial. Havia perdido a principal fonte de segurança e de afeto: os pais. Precisava de uma terapeuta que pudesse oferecer- Ihe parte do que havia perdido, que pudesse conter sua ansiedade e agonia, que pudesse aceitá-lo como era.

Após um ano, a psicoterapia foi interrompida, pois eu estava deixando de atender na instituição. Isso havia sido informado para Léo e para a tia, desde o contrato inicial. Então encaminhei-o para iniciar uma psicoterapia com outro psicólogo.

\section{Considerações Finais}

Desde quando a AIDS foi descoberta, ocorreram grandes avanços no tratamento médico, psicológico e social, com grandes melhoras no prognóstico, na evolução e na qualidade de vida desses pacientes. Não obstante, para boa parte da população, essa enfermidade representa uma grande ameaça, pois o seu diagnóstico pode ser sentido como a anunciação da morte.

Este estudo ajudou a compreender que a vivência de uma doença grave pode remeter a perdas e lutos pregressos, da mesma forma que contém ameaças de morte. A criança relatada enfrentava a gravidade de sua enfermidade e o luto pelos pais, falecidos em decorrência de complicações da AIDS. Assim, as fantasias sobre sua doença misturavam-se às fantasias relacionadas com a morte dos genitores. Léo sentia-se culpado tanto por sua enfermidade, quanto pela perda dos pais, o que produzia sentimentos de abandono e desamparo.

Apesar de ter nascido soropositivo, só veio a saber dessa condição aos sete anos de idade. Tinha uma doença grave, sem cura, alvo de preconceito, da qual procurava se esconder e se resguardar perante os outros. Também tentava elaborar a mudança de papéis familiares, já que a tia passara a ser sua cuidadora, e temia não ser suficientemente amado por ela e pela terapeuta.

No processo psicoterápico, a criança utilizara inicialmente a negação, manifestando posteriormente sua raiva e revolta, as quais, muitas vezes, oscilavam e sobrepunham-se. A ludoterapia pode ter ajudado na elaboração de alguns psicodinamismos inconscientes. A terapeuta procurou aceitar a sua destrutividade, permitindo que o espaço lúdico e terapêutico funcionasse como um ambiente criativo e facilitador para a expressão de sua ansiedade e fantasias, para o seu desenvolvimento emocional. Léo foi gradualmente mudando sua maneira de se expressar, de sentir, dispondo de recursos internos mais elaborados para lidar com seus conflitos. Após um ano de terapia, já expressava com mais facilidade suas emoções, a raiva e a agressividade, sendo mais espontâneo e alegre.

Trabalhar com um menino com o diagnóstico de AIDS provocou na psicoterapeuta muitas fantasias relacionadas com a possibilidade da morte do paciente. Algumas vezes, diante de faltas à consulta, a psicóloga imaginava que pudesse ter piorado e que algo de grave teria acontecido com ele, produzindo na terapeuta sentimentos de impotência e reflexões sobre a própria morte.

\section{Referências}

Aberastury, A. (1984). A percepção da morte nas crianças. In A. Aberastury et al. A percepção da morte na criança e outros escritos (pp.128-139). Porto Alegre: Artes Médicas.

Aronson, S. (1996). The bereavement process in children of parents with AIDS. Psychoanalytic Study of the Child, 51, 422-435. 
Baricca, A. M. (1998). Histórias vividas por crianças com AIDS. Dissertação de mestrado não-publicada, Instituto de Psicologia, Universidade de São Paulo.

Botega, N. J. (2006). Reação à doença e à hospitalização. In N. J. Botega (Org.). Prática psiquiátrica no hospital geral: interconsultaeemergência (2a ed., pp.49-66). Porto Alegre: Artmed.

Calil, R. C. C., \& Arruda, S. L. S. (2004). Discussão da pesquisa qualitativa com ênfase no método clínico. In S. Grubits \& J. A. V. Noriega (Orgs.), Método qualitativo: epistemologia, complementariedades e campos de aplicação (pp.173-213). São Paulo: Vetor.

Cassorla, R. (1991). Como lidamos com o morrer. In R. Cassorla (Org.). Da morte: estudos brasileiros (pp.17-23). Campinas: Papirus.

Cedaro, J. J. (2005). A ferida na alma: os doentes de AIDS sobo ponto de vista psicanalítico. Tese de doutorado não-publicada, Instituto de Psicologia, Universidade de São Paulo.

Celeri, E. H. R. V., \& Outeiral, J. (2005). Existiria o equivalente ao instinto de morte no pensamento de Winnicott? Algumas reflexões sobre ser, não-ser e solidão essencial. In J. Outeiral, S. Hisada, R. H. C. N. Gabriades \& A. M. Ferreira (Orgs.), Winnicott: Seminários Brasileiros (pp.434-440). Rio de Janeiro: Revinter.

Ferreira, C. V. L. (1992). Conversando com o paciente HIVpositivo: um estudo clínico. Tese de doutorado nãopublicada, Faculdade de Ciências Médicas, Universidade Estadual de Campinas.

Freud, S. (1974a). Luto e melancolia. In S. Freud. Obras psicológicas completas de Sigmund Freud (Vol.14, pp.271-291). Rio de Janeiro: Imago. (Originalmente publicado em 1915)

Freud, S. (1974b). Reflexões para os tempos de guerra e morte. In S. Freud. Obras psicológicas completas de Sigmund Freud (Vol.14, pp.327-339). Rio de Janeiro: Imago. (Originalmente publicado em 1915).

Gewirtz, A., \& Gossart-Walker, S. (2000). Home-based treatment for children and families affected by HIV and AIDS: dealing with stigma, secrecy, disclosure, and loss. Child Adolescent Psychiatric Clinics North America, 9 (2), 313-330.

Gunther, M., Crandles, S., Williams, G., \& Swain, M. (1998). A place called HOPE: group psychotherapy for adolescents of parents with HIV/AIDS. Child Welfare, 77 (2), 251-271.

Hug-Helmut, H. (1998). El concepto de muerte en el niño. Revista Uruguaia Psicoanalítica, Montevideo, 88, 7-21.

lencarelli, A. B. (1997). A morte anunciada de uma criança. Boletim Científico SPRJ, Rio de Janeiro, 18 (3),425-429.

Jacintho, A. C. A., Celeri, E. H. R. V., \& Straus, L. (2006). Interconsulta em psiquiatria infantil. In N. J. Botega (Org.), Prática psiquiátrica no hospital geral: interconsultae emergência (2a ed., pp.521-532). Porto Alegre: Artmed.

Klein, M. (1980). A técnica psicanalítica através do brinquedo: sua história e significado. In M. Klein, P. Heimann \& R. E. Money-Kyrle (Orgs.), Novas tendências da psicanálise (pp.25-48). Rio de Janeiro:Zahar Editores. (Originalmente publicado em 1955)

Kübler-Ross, E. (1989). Sobre a morte e o morrer. São Paulo: Martins Fontes.
Moraes, M. J., Oliveira, A. C. P., \& Tostes, M. A. (2006). AIDS e psiquiatria. In N. J. Botega (Org.), Prática psiquiátrica no hospital geral: interconsulta e emergência (2a ed., pp.373-394). Porto Alegre: Artmed.

Moreno, D. M. F. C., \& Reis, A. O. A. (2002). O momento da comunicação do resultado sorológico para o HIV sob a ótica winnicottiana. Pulsional Revista de Psicanálise, 15 (156), 20-25.

Newman, A. (2003). As idéias de D. W. Winnicott: um guia. Rio de Janeiro: Imago.

Raimbault, G. (1979). A criança e a morte: crianças doentes falam da morte: problemas da clínica do /uto. Rio de Janeiro: Francisco Alves.

Silva, M. C. P. (2005). O mecanismo de idealização como parte do processo de introjeção do objeto bom. In Asociación Psicanalítica de Buenos Aires (Org.), Marcas de época en el psicoanálisis con niños y adolescentes. VII Jornada del Departamento de Niñez y Adolescencia (pp.241-252). Buenos Aires.

Souza, A. N. D. (1992). Grupo de reflexão multiprofissional em AIDS: uma estratégia em psicologia médica. In J. Mello Filho et al. Psicossomática hoje (pp.320-324). Porto Alegre: Artes Médicas.

Taschetto, A. R., Teixeira, L. M., \& Kiperman, A. (1994). Considerações a respeito do conceito de morte para Winnicott. In Grupos de Estudos Psicanalíticos de Pelotas (Org.), Anais do III Encontro Latino-Americano sobre o pensamento de D. W. Winnicott (Vol. 2, pp.190-196). Gramados, RS.

Télis, C. T. (1991). Comportamento psicológico de pacientes com câncer avançado. In R. Cassorla (Org.), Da morte: estudos brasileiros (pp.105-117). Campinas: Papirus.

Tonin, S. Q. C. (2001). A psicanálise de José: morte e ressureição. Trieb, 10, 107-122.

Torres, W. C. (2002). A criança diante da morte: desafios. São Paulo: Casa do Psicólogo.

Turato, E. R. (2003). Tratado da metodologia da pesquisa clínico-qualitativa: construção teórico-epistemológico, discussão comparada e aplicação nas áreas da saúde e humanas. Petrópolis: Vozes.

Weininger, O. (1996). Being and not being: Clinical applications of the death instinct. Madison: IUP.

Winnicott, D. W. (1983). A capacidade para estar só. In D. W. Winnicott. Oambientee os processos de maturação:estudos sobre a teoria do desenvolvimento emocional (pp.31-37) Porto Alegre: Artes Médicas. (Originalmente publicado em 1958).

Winnicott, D. W. (2000). Fear of breakdown. In C. Winnicott, R. Sheperd, M. Davies (Eds.), Psycho-analytic explorations: D. W. Winnicott (6th ed., pp.87-95). Cambridge (USA): Harvard University Press. (Originalmente escrito aproximadamente em 1963).

Winnicott, D. W. (2000). The use of an object and relating through identifications. In C. Winnicott, R. Sheperd \& M. Davies (Eds.), Psycho-analytic explorations: D. W. Winnicott (6th ed., pp.218-227). Cambridge (USA): Harvard University Press. (Originalmente publicado em 1968).

Recebido em: 21/11/2005

Versão final reapresentada em: 14/4/2006

Aprovado em: 9/5/2006 
